\title{
Grief After Euthanasia and Physician-Assisted Suicide
}

\author{
A Systematic Review
}

\author{
Karl Andriessen ${ }^{1} \oplus$, Karolina Krysinska ${ }^{1,2}$, Dolores Angela Castelli Dransart ${ }^{3}$, \\ Luc Dargis ${ }^{4}$, and Brian L. Mishara ${ }^{4,5}$
}

\begin{abstract}
${ }^{1}$ Centre for Mental Health, School of Population and Global Health, The University of Melbourne, Parkville, VIC, Australia ${ }^{2}$ Orygen, The National Centre of Excellence in Youth Mental Health, The University of Melbourne, Parkville, VIC, Australia ${ }^{3}$ School of Social Work Fribourg, HES-SO, University of Applied Sciences and Arts Western Switzerland, Fribourg, Switzerland ${ }^{4}$ Centre for Research and Intervention on Suicide, Ethical Issues and End of Life Practices (CRISE), Montréal, Canada ${ }^{5}$ Psychology Department, Université du Québec à Montréal, Canada
\end{abstract}

\begin{abstract}
Background: Several countries have regulated euthanasia and physician-assisted suicide (PAS). Research has looked at the experiences of patients, family, and professionals. However, little is known of the effects on bereaved individuals. Aims: We aimed to assess (a) what is known about the grief and mental health of people bereaved by euthanasia or PAS and (b) the quality of the research. Method: Systematic review according to PRISMA guidelines with searches in Cinahl, Embase, PsycINFO, Pubmed, and Scopus. Results: The searches identified 10 articles (eight studies), and the study quality was fair. People bereaved by euthanasia/PAS generally had similar or lower scores on measures of disordered grief, mental health, and posttraumatic stress compared with those who died naturally. Lack of social support and secrecy may compound their grief. Being involved in the decision-making process and having the feeling of honoring the deceased's will may facilitate their grief. Limitations: Studies used self-reports from non-random self-selected participants, were retrospective, and were conducted in only three countries. Conclusion: There is little evidence of increased risk of adverse grief or mental health outcomes in people bereaved by euthanasia/ PAS. As more countries legalize assisted dying, high-quality studies of the factors that may hinder or facilitate the grief process are needed.
\end{abstract}

Keywords: assisted suicide, bereavement, euthanasia, grief, medical assistance in dying, mental health, systematic review

Over the past decades several countries and states have passed legislation to legalize euthanasia and physician-assisted suicide (PAS; Dyer, White, \& Rada, 2015; Emanuel, Onwuteaka-Philipsen, Urwin, \& Cohen, 2016). Both types of assistance in dying hasten an individual's death. In the case of euthanasia, a physician intentionally ends the life of a patient at his/her request, usually by the administration of a lethal drug. In the case of PAS, the physician prescribes or supplies the lethal drug to the patient, at his/her request, with the patient performing the action that will cause his/her own death (Emanuel et al., 2016).

Euthanasia and PAS were already practiced in Antiquity in the context of a "good death" and the first attempts to create a legal framework occurred about 100 years ago, in 1906 in the US states of Ohio and Iowa (Dowbiggin, 2005; Emanuel, 1994). Advocacy groups within the general population and the judiciary have driven legal changes, and currently, euthanasia and/or PAS can be legally practiced in The Netherlands, Belgium, Luxembourg, Colombia, and Canada (Dyer et al., 2015; Kelleher, Chambers, Corcoran, Keeley, \& Williamson, 1998; Kelleher et al., 1995).
PAS is allowed in eight US states (California, Colorado, District of Columbia, Hawaii, Montana, Oregon, Vermont, and Washington; https://www.deathwithdignity.org/), as well as in Switzerland, and most recently, in the Australian state of Victoria (Victoria State Government, 2019).

There is variety in the number of medically assisted deaths across countries. For example, PAS accounted for approximately $0.4 \%$ of deaths in Oregon and Washington in 2015 (Emanuel et al., 2016), and 1.4\% in Switzerland (most recent data, year 2016; Bundesamt für Statistik, 2019). Euthanasia accounted for approximately $2.1 \%$ of deaths in Belgium (in 2018), and $4.4 \%$ in The Netherlands (in 2017) (Federale Overheidsdienst Volksgezondheid, 2019; Rijksoverheid, 2019). While eligibility criteria and application procedures vary across countries (for overviews, see: Dyer et al., 2015; Mishara \& Kerkhof, 2018), access is usually limited to mentally competent patients whose suffering is considered to be unbearable.

Research in this field has focused on various aspects, such as the moral and ethical aspects (Bélanger et al., 2019; Kouwenhoven, van Thiel, van der Heide, Rietjens, 
\& van Delden, 2019; Mishara \& Weisstub, 2013; Speijer \& Diekstra, 1980), public acceptance (Cohen et al., 2006; Frey \& Hans, 2016; Marcoux, Mishara, \& Durand, 2007; Poma et al., 2015), and the legal status and epidemiology of euthanasia and PAS (Cohen, Dierickx, Penders, Deliens, \& Chambaere, 2018; Steck, Egger, Maessen, Reisch, \& Zwahlen, 2013). Studies have also looked at the views of individuals requesting medical assistance in dying (Dees, Vernooij-Dassen, Dekkers, Vissers, \& Van Weel, 2011; Hendry et al., 2013; Lapierre et al., 2018), family involvement in end-of-life decision-making (Gamondi, 2017; Gamondi, Pott, Preston, \& Payne, 2018; Kimsma \& Van Leeuwen, 2007; Pott, Dubois, Currat, \& Gamondi, 2011), and the perceptions of physicians (Emanuel et al., 2016; Ganzini, Dobscha, Heintz, \& Press, 2003) and other professional caregivers (Castelli Dransart, Scozzari, \& Voélin, 2017).

While scholars, clinicians, and ethicists have argued that a good death would require avoidance of preventable harm to others (Kuitert, 1994; Leenaars et al., 2001; Speijer \& Diekstra, 1980), there are several reasons why a death through euthanasia or PAS may be thought to have the potential of compounding the grief of bereaved individuals (Beder, 1998). Providing long-term care for a chronically ill family member may involve many responsibilities regarding practical, social, emotional, and legal support, and may exhaust the family caregiver (Carr, 2003). Euthanasia and PAS are usually considered unnatural deaths, as such they may be associated with increased risk of social isolation, stigma, disordered grief, depression, posttraumatic stress disorder (PTSD), and suicidal behavior (Dyregrov, Cimitan, \& De Leo, 2014; Kristensen, Weisæth, \& Heir, 2012; Pitman, Rantell, Marston, King, \& Osborn, 2017). Investigations by police, medical examiners, or coroners, as well as dealing with the media may add to the psychosocial stress of the loss (Chapple, Ziebland, Simkin, \& Hawton, 2013; Spillane, Matvienko-Sikar, Larkin, Corcoran, \& Arensman, 2019). By contrast, being involved in endof-life care, having the opportunity to say goodbye and to prepare for the loss, which are possible with euthanasia and PAS, have been associated with better bereavement adjustment (Wright et al., 2008).

In contrast to the large number of research studies on bereavement following deaths by suicide or other causes, little is known of the effects of euthanasia and PAS on those who are bereaved, and to date no systematic review is available. The present review aims to fill this gap by reviewing studies on the grief and mental health of people bereaved by euthanasia or PAS, and to appraise the quality of the research in this field. This review does not entail a stance pro or contra euthanasia or PAS. Its findings may inform those involved in this field, including researchers, clinicians, family caregivers, and individuals considering euthanasia or PAS.

\section{Method}

The systematic review was conducted according to the PRISMA guidelines (http://www.prisma-statement.org/; Moher, Liberati, Tetzlaff, Altman, \& Prisma Group, 2009), and comprised searches in five databases: Cinahl, Embase, PsycINFO, Pubmed, and Scopus. For example, PubMed was searched with the following query: $((()(()((()($ Bereavement [MH] OR (Griev*[TW] OR "anticipatory grief” [TW] OR preparedness[TW] OR bereavement[TW] OR Bereave $^{*}[\mathrm{TW}]$ OR Griev ${ }^{*}[\mathrm{TW}]$ OR Mourn ${ }^{*}[\mathrm{TW}]$ OR grief[TW] OR "loss survivor" [TW] )) AND $(((((($ Euthanasi*[TW] OR (Assisted[TW] AND Suicid*[TW]) OR "death with dignity" [TW] OR "hasten death" [TW] OR "right to die"[TW] OR "Medical Assistance in Dying" [TW] OR "end of life" $[\mathrm{TW}[())))))))))$ ) NOT (veteri* OR "animal euthanasia"))))))). The number of databases and their scope show the completeness and rigor of the approach. The number of keywords and the use of controlled vocabulary and natural language terms are in line with Cochrane recommendations (Higgins \& Green, 2011). Similar searches were conducted in the other databases (search strings are available upon request). There was no restriction on language, location, or year of publication. The search was limited to peer-reviewed journals and conducted in February 2019.

\section{Inclusion and Exclusion Criteria}

Two researchers (KA, KK) independently assessed titles and abstracts for eligibility. Any disagreement was resolved through discussion. Original studies were included if: (a) the study population consisted of people bereaved by a death through euthanasia or PAS; (b) the study used quantitative, qualitative, or mixed methods; and (c) the study reported data on the grief or mental health of the study population. We excluded: (a) studies on other types of bereavement or not involving humans; (b) studies applying other methods such as case reports; and (c) studies without original data, such as reviews and opinion papers. The references of the selected and review papers were hand-searched to identify additional studies. Figure 1 depicts the search and selection process.

\section{Data Extraction}

Three researchers (KA, KK, DACD) independently extracted the following data from the selected papers: author, year and location (country), study design, eligibility criteria, sample size, participants' age and sex distribution, participants' time since the bereavement and relationship to the deceased, setting of the study, outcome measures, 


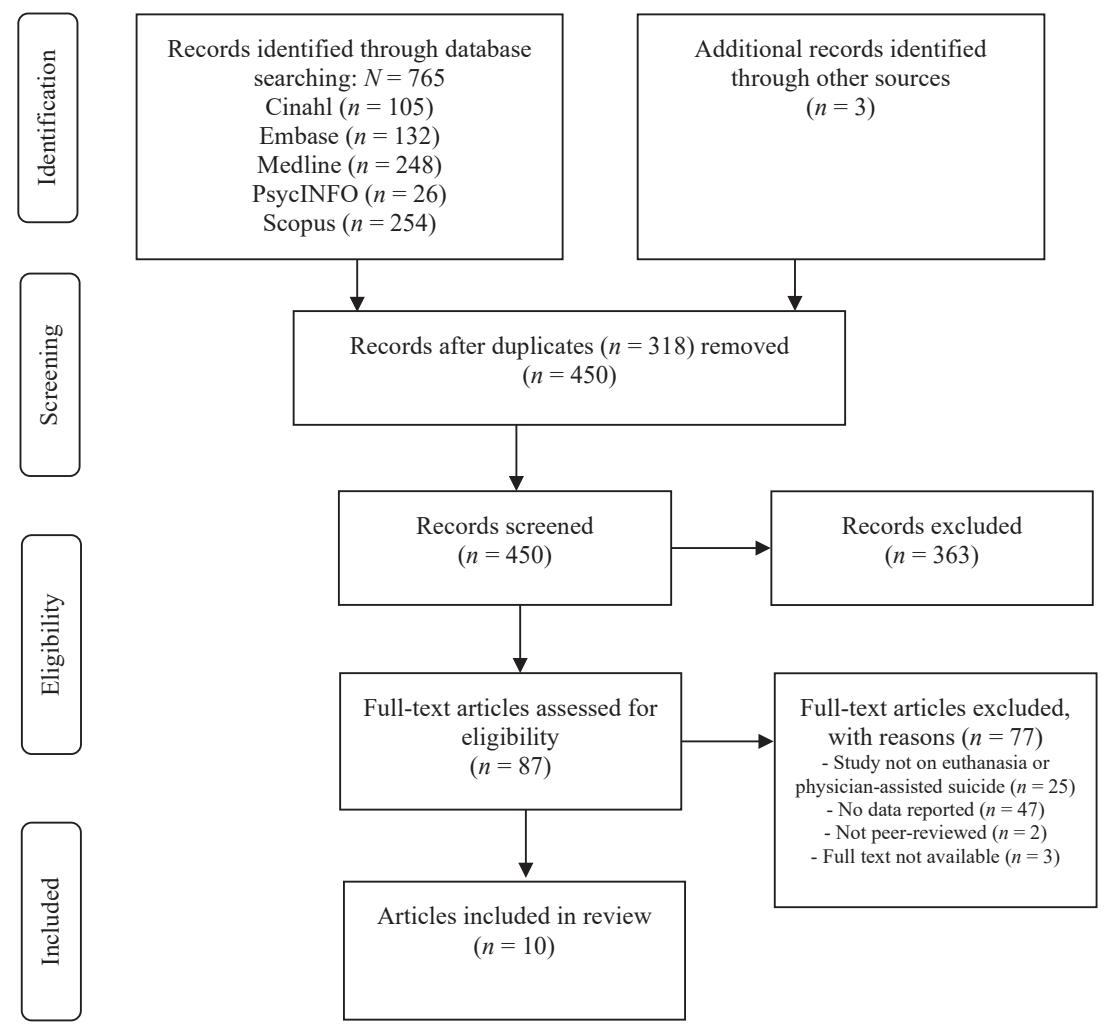

Figure 1. PRISMA flow diagram

names of the instruments used, and main results of the study. Any disagreement was resolved through discussion.

\section{Quality Assessment}

Two researchers (KA, DACD) independently assessed the quality of the included studies. Discussion with a third researcher (KK) settled any disagreement. The quantitative studies were assessed with the Newcastle-Ottawa Quality Assessment Form for Cohort Studies (Wells et al., n.d.). The instrument consists of three components: selection (four items), comparability (one item), and outcome (three items). The total quality of a study was categorized as good, fair, or poor depending on the number of "stars" allocated to each category. The qualitative studies were assessed with the Consolidated Criteria for Reporting Qualitative Research (COREQ; Tong, Sainsbury, \& Craig, 2007). The instrument consists of 32 items structured in three domains: research team and reflexivity (eight items), study design (15 items), and analysis and findings (nine items). To compare the study quality, we totaled the number of reported items, in each domain, and for all items.

\section{Results}

\section{Study Characteristics}

The systematic review included 10 articles published between 1995 and 2018 and half of these were published in the last 5 years (Table A1 in the appendix). These 10 articles represented eight studies as three articles were based on one study sample (Wagner, Boucsein, \& Maercker, 2011; Wagner, Keller, Knaevelsrud, \& Maercker, 2012; Wagner, Müller, \& Maercker, 2012). All research was conducted in three countries: five articles from two research teams in Switzerland (Gamondi, Pott, Forbes, \& Payne, 2013; Gamondi et al., 2018; Wagner et al., 2011; Wagner, Keller, et al., 2012; Wagner, Müller, et al., 2012), three from the US (Ganzini, Goy, Dobscha, \& Prigerson, 2009; Srinivasan, 2018; Starks et al., 2007), and two from The Netherlands (Swarte, Van Der Lee, Van Der Bom, Van Den Bout, \& Heintz, 2003; van den Boom, 1995). All studies included bereaved family members, and half of them also included close friends. All studies focused on adult populations across the lifespan, although the mean age was about 60 in half of the studies. No study included children or adolescents. The percentage of females ranged from $54 \%$ to $69 \%$. The time since bereavement varied across studies: Seven articles reported a mean between 11 and 24 months. 
There were five quantitative, cross-sectional studies (Ganzini et al., 2009; Swarte et al., 2003; Wagner et al., 2011; Wagner, Keller, et al., 2012; Wagner, Müller, et al., 2012). Two studies involved a control group of family members and/or friends bereaved by natural, non-medically assisted deaths (Ganzini et al., 2009; Swarte et al., 2003). One study compared the findings against the general (not necessarily bereaved) population (Wagner, Müller, et al., 2012). All assessed disordered grief, for example, through the Inventory of Complicated Grief-Short Form (ICG-SF; Prigerson \& Jacobs, 2001), and applied various mental health and trauma-related instruments such as the Impact of Event Scale (IES; Horowitz, Wilner, \& Alvarez, 1979; Weiss \& Marmar, 1997). No study specifically assessed nondisordered grief or suicidal behavior as an outcome. Five studies collected qualitative data through semistructured interviews (Gamondi et al., 2013; 2018; Srinivasan, 2018; Starks et al., 2007) or with a questionnaire and interview (van den Boom, 1995). These qualitative studies explored the involvement of bereaved individuals in the decision-making process and their grief experiences after the death of their family member or friend.

\section{Quality Assessment}

Overall the methodological quality of the quantitative studies was fair (Table 1). For all studies, the sample selection was rated as "somewhat representative," ascertainment of exposure was reliable, and studies controlled for basic confounders such as age and sex in their design or analysis. However, only two studies involved a control group (Ganzini et al., 2009; Swarte et al., 2003), and all studies relied on self-report measures only.

The qualitative studies reported about half of the COREQ items (Tong et al., 2007) (Table 2). Most items in Domain 3 (analysis and findings), and about half of the items in Domain 2 (study design) were reported. Items in Domain 1 (research team and reflexivity) were reported the least.

\section{Disordered Grief Outcomes}

Three studies compared grief scores of those bereaved by euthanasia or PAS against a control group, and reported similar scores (Ganzini et al., 2009; Wagner, Müller, et al., 2012) or lower scores in the groups bereaved by euthanasia or PAS (Swarte et al., 2003). Ganzini et al. (2009) found no difference between the two groups regarding prevalence of prolonged grief disorder $(2 \%)$ or grief symptom severity, measured by the ICG-SF (Prigerson \& Jacobs, 2001). Wagner, Müller, et al. (2012) found a prevalence of $4.9 \%$ among the PAS bereaved, which was comparable to the Swiss general population. There was no correlation between duration of disease and complicated grief symptoms (Wagner, Müller, et al., 2012). The study by Swarte et al. (2003) found higher scores on the Texas Revised Inventory of Grief (Faschingbauer, Zisook, \& DeVaul, 1987), indicating lower current grief feelings, and lower scores on the Inventory of Traumatic Grief (Boelen, Van den Bout, De Keijser, \& Hoijtink, 2003), indicating lower symptoms of traumatic grief in the study group. More bereaved people in the control group met the criteria of traumatic grief than in the euthanasia/PAS group (5.7\% vs. $2.1 \%)$, indicating a statistically and clinically significant difference (Swarte et al., 2003).

Some participants in qualitative studies attributed difficulties in their grief process to having experienced medi$\mathrm{cal} /$ technical complications in the dying process (Starks et al., 2007; van den Boom, 1995). Clinical complicated grief symptoms were found in $6 \%$ of participants, with symptoms lasting from 1 to 3 years (Starks et al., 2007). Some participants reported that being in conflict with the assisted dying decision, anxiety experienced with the scheduling of the death, or difficulties in dealing with the stigma associated with the death hindered their grief process (Gamondi et al., 2015; Srinivasan, 2018; Starks et al., 2007). However, agreement with the decision, having the opportunity to say goodbye, and the thought that the dying family member avoided prolonged suffering eased the grief (Gamondi et al., 2015; Srinivasan, 2018; Starks et al., 2007).

\section{Mental Health and Posttraumatic Stress Outcomes}

Three studies reported similar or lower mental health scores in the bereaved study group compared with a control group (Ganzini et al., 2009; Swarte et al., 2003; Wagner, Müller, et al., 2012). Ganzini et al. (2009) found no differences between the PAS group and the control group regarding major depressive disorder (11\% in PAS group), severity of current depressive symptoms (6\% in PAS group, measured with the Beck Depression Inventory [BDI]; Beck, Steer, \& Carbin, 1988), and having received mental health care after the death of their family member $(38 \%$ in PAS group). Also, Swarte et al. (2003) found no difference between the two groups on the Symptom Checklist (SCL-90; Arrindell \& Ettema, 1986) and no difference on the Depressive Adjective Checklist (DACL; Lubin, 1965). However, Wagner, Müller, et al. (2012) reported a higher prevalence of mental health problems in the PAS group compared with the general Swiss population. The prevalence of depression in the PAS group was $16 \%$, and the 
Table 1. Quality assessment ${ }^{a}$ of included quantitative studies

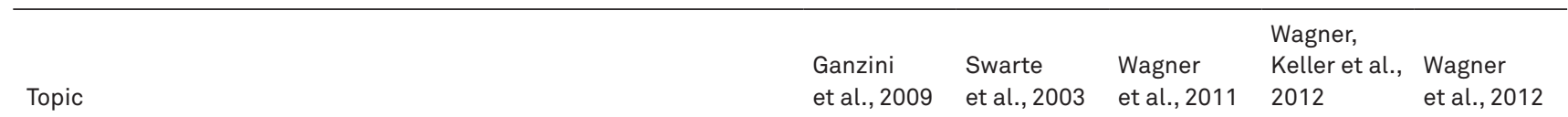

\section{Selection}

1) Representativeness of the exposed cohort
a) Truly representative (one star)
b) Somewhat representative (one star)
c) Selected group
d) No description

2) Selection of the non-exposed cohort
a) Drawn from the same community as the exposed cohort (one star)
$x$
$x$
b) Drawn from a different source
c) No description

$\mathrm{n} / \mathrm{a}$

$x$

$x$
b) Structured interview (one star)
c) Written self-report
d) No description
e) Other

a) Secure record (e.g., surgical record) (one star)

4) Demonstration that outcome of interest was not present at start of study
a) Yes (one star)
b) No

$x$

$X$

\section{Comparability}

1) Comparability of cohorts on the basis of the design or analysis controlled for confounders
a) The study controls for age, sex and marital status (one star)
$x$
$x$
$x$
$x$
c) Controls are not comparable

\section{Outcome}

1) Assessment of outcome
a) Independent blind assessment (one star)
b) Record linkage (one star)
c) Self-report
d) No description
e) Other

$x$

2) Was follow-up long enough for outcomes to occur?
a) Yes (one star)
b) No
c) Indicate the mean duration of follow-up and a brief rationale for the assessment above

$x$
$X$

$X$

$x$

3) Adequacy of follow-up of cohorts

a) Complete follow-up, all subjects accounted for (one star)

b) Subjects lost to follow-up unlikely to introduce bias, number lost less than or equal to $20 \%$ or description of those lost suggested no different from those followed (one star)

c) Follow-up rate less than $80 \%$ and no description of those lost

d) No statement

$\mathrm{n} / \mathrm{a}$

$n / a$

$n / a$

$\mathrm{n} / \mathrm{a}$

$n / a$

Table continued next page 
Table 1. continued

\begin{tabular}{|c|c|c|c|c|c|}
\hline Topic & $\begin{array}{l}\text { Ganzini } \\
\text { et al., } 2009\end{array}$ & $\begin{array}{l}\text { Swarte } \\
\text { et al., } 2003\end{array}$ & $\begin{array}{l}\text { Wagner } \\
\text { et al., } 2011\end{array}$ & $\begin{array}{l}\text { Wagner, } \\
\text { Keller et al., } \\
2012\end{array}$ & $\begin{array}{l}\text { Wagner } \\
\text { et al., } 2012\end{array}$ \\
\hline \multicolumn{6}{|l|}{ Stars } \\
\hline Selection & 4 & 4 & 3 & 3 & 3 \\
\hline Comparability & 2 & 2 & 1 & 1 & 1 \\
\hline Outcome & 1 & 1 & 1 & 1 & 1 \\
\hline Rating & fair & fair & fair & fair & fair \\
\hline
\end{tabular}

Note. ${ }^{a}$ Newcastle-Ottawa Quality Assessment Form for Cohort Studies (Wells et al., n.d.).

A study can be given a maximum of one star for each numbered item within the selection and outcome categories. A maximum of two stars can be given for comparability. Thresholds for converting the Newcastle-Ottawa scales to AHRQ standards (good, fair, and poor): Good quality: 3 or 4 stars in selection domain AND 1 or 2 stars in comparability domain AND 2 or 3 stars in outcome/exposure domain. Fair quality: 2 stars in selection domain AND 1 or 2 stars in comparability domain AND 2 or 3 stars in outcome/exposure domain. Poor quality: 0 or 1 star in selection domain OR 0 stars in comparability domain OR 0 or 1 stars in outcome/exposure domain. $\mathrm{n} / \mathrm{a}=$ not applicable

Table 2. Quality assessment ${ }^{a}$ of included qualitative studies

\begin{tabular}{|c|c|c|c|c|c|}
\hline Topic & $\begin{array}{l}\text { Gamondi } \\
\text { et al., } 2013\end{array}$ & $\begin{array}{l}\text { Gamondi } \\
\text { et al., } 2018\end{array}$ & $\begin{array}{l}\text { Srinivasan, } \\
2018\end{array}$ & $\begin{array}{l}\text { Starks } \\
\text { et al., } 2007\end{array}$ & $\begin{array}{l}\text { Van Den } \\
\text { Boom, } 1995\end{array}$ \\
\hline \multicolumn{6}{|l|}{ Domain 1: Research team and reflexivity } \\
\hline \multicolumn{6}{|l|}{ Personal characteristics } \\
\hline 1 Interviewer/facilitator & & & p. 2 & & \\
\hline 2 Credentials & p. 146 & p. 1085 & & & \\
\hline 3 Occupation & p. 146 & & p. 2 & & \\
\hline \multicolumn{6}{|l|}{4 Gender } \\
\hline \multicolumn{6}{|l|}{5 Experience and training } \\
\hline \multicolumn{6}{|l|}{ Relationship with participants } \\
\hline \multicolumn{6}{|l|}{6 Relationship established } \\
\hline \multicolumn{6}{|l|}{7 Participant knowledge of the interviewer } \\
\hline \multicolumn{6}{|l|}{8 Interviewer characteristics } \\
\hline \multicolumn{6}{|l|}{ Domain 2: Study design } \\
\hline \multicolumn{6}{|l|}{ Theoretical framework } \\
\hline 9 Methodological orientation and theory & p. 147 & p. 1087 & p. 2 & & \\
\hline \multicolumn{6}{|l|}{ Participant selection } \\
\hline 10 Sampling & p. 147 & p. 1086 & p. 2 & p. 107 & \\
\hline 11 Method of approach & & p. 1086 & p. 2 & p. 107 & \\
\hline 12 Sample size & p. 147 & p. 1086 & p. 2 & p. 110 & p. 177 \\
\hline 13 Non-participation & p. 147 & & p. 2 & & \\
\hline \multicolumn{6}{|l|}{ Setting } \\
\hline 14 Setting of data collection & & p. 1086 & & p. 110 & \\
\hline \multicolumn{6}{|l|}{15 Presence of non-participants } \\
\hline 16 Description of sample & p. 148 & p. 1088 & & p. 110-11 & p. 177 \\
\hline \multicolumn{6}{|l|}{ Data collection } \\
\hline 17 Interview guide & p. 147 & & & p. 110 & \\
\hline 18 Repeat interviews & & & & p. 110 & \\
\hline 19 Audio/visual recording & p. 147 & p. 1086 & p. 2 & p. 110 & \\
\hline 20 Field notes & & p. 1087 & p. 2 & & \\
\hline 21 Duration & & p. 1086 & p. 2 & & p. 177 \\
\hline \multicolumn{6}{|l|}{22 Data saturation } \\
\hline 23 Transcripts returned & & p. 1087 & & & \\
\hline
\end{tabular}


Table 2. continued

\begin{tabular}{|c|c|c|c|c|c|}
\hline Topic & $\begin{array}{l}\text { Gamondi } \\
\text { et al., } 2013\end{array}$ & $\begin{array}{l}\text { Gamondi } \\
\text { et al., } 2018\end{array}$ & $\begin{array}{l}\text { Srinivasan, } \\
2018\end{array}$ & $\begin{array}{l}\text { Starks } \\
\text { et al., } 2007\end{array}$ & $\begin{array}{l}\text { Van Den } \\
\text { Boom, } 1995\end{array}$ \\
\hline \multicolumn{6}{|l|}{ Domain 3: Analysis and findings } \\
\hline \multicolumn{6}{|l|}{ Data analysis } \\
\hline 24 Number of data coders & p. 147 & p. 1087 & p. 3 & p. 111 & \\
\hline 25 Description of the coding tree & p. 147 & p. 1087 & p. 3 & p. 111 & \\
\hline 26 Derivation of themes & p. 147 & p. 1087 & p. 3 & p. 111 & p. 178 \\
\hline 27 Software & & & p. 3 & p. 111 & \\
\hline \multicolumn{6}{|l|}{28 Participant checking } \\
\hline \multicolumn{6}{|l|}{ Reporting } \\
\hline 29 Quotations presented & pp. $149-150$ & p. 1089 & pp. 3-7 & pp. 112-24 & \\
\hline 30 Data and findings consistent & pp. $149-150$ & pp. 1087-90 & pp. 3-7 & pp. 112-24 & \\
\hline 31 Clarity of major themes & pp. $149-150$ & pp. 1087-90 & pp. 3-7 & pp. 112-24 & pp. 181-82 \\
\hline 32 Clarity of minor themes & & p. 1091 & & pp. 125 & \\
\hline Domain 1: Research team and reflexivity & $2 / 8 \quad(25 \%)$ & $1 / 8(12.5 \%)$ & $2 / 8 \quad(25 \%)$ & $0 / 8 \quad(0 \%)$ & $0 / 8 \quad(0 \%)$ \\
\hline Domain 2: Study design & $7 / 15(47 \%)$ & 10/15 (67\%) & $8 / 15(53 \%)$ & $8 / 15(53 \%)$ & $3 / 15(20 \%)$ \\
\hline Domain 3: Analysis and findings & $6 / 9(67 \%)$ & $7 / 9 \quad(78 \%)$ & $7 / 9 \quad(78 \%)$ & $8 / 9$ (89\%) & $2 / 9 \quad(22 \%)$ \\
\hline Total & $15 / 32(47 \%)$ & $18 / 32(56 \%)$ & $17 / 32(53 \%)$ & $16 / 32(50 \%)$ & $5 / 32(16 \%)$ \\
\hline
\end{tabular}

Note. ${ }^{\mathrm{a}}$ Consolidated Criteria for Reporting Qualitative Research (COREQ) (Tong et al., 2007).

prevalence of anxiety was $6 \%$. Also, $8 \%$ of the participants reported impaired general mental health and $22 \%$ clinically relevant impaired physical health. There were no gender differences. By contrast, the prevalence of major depressive disorder and subsyndromal depression was $2.3 \%$ and $9.3 \%$, respectively, in the Swiss population (Wagner, Müller, et al., 2012).

In the qualitative studies, van den Boom (1995) found no association between way of dying and depression. Some participants in the study by Starks et al. (2007) reported anxiety and exhaustion. While some participants in the study by Srinivasan (2018) reported anxiety in scheduling the death, the dying experience was deemed more comforting owing to a sense of control regarding the death.

Two studies reporting posttraumatic stress outcomes revealed mixed findings. In one study (Swarte et al., 2003), the family and friends bereaved by euthanasia or PAS had less posttraumatic stress reactions measured by the IES (Horowitz et al., 1979) than those bereaved by natural causes of death (Swarte et al., 2003). In the other study, Wagner, Müller, et al. (2012) found a prevalence of PTSD of $13 \%$ and subthreshold PTSD of $6.5 \%$, while the prevalence of PTSD in the general Swiss population was $0.7 \%$ and subthreshold PTSD was $4.2 \%$. There was a negative correlation between posttraumatic stress symptoms and the age of the deceased but not with duration of disease. Type of relationship (partner vs. parent) and gender of the bereaved person were not related to posttraumatic stress symptoms (Wagner, Müller, et al., 2012).

Those bereaved who met the diagnostic criteria of PTSD were more likely to have experienced emotional dif- ficulties during the forensic examination than those who did not meet the diagnostic criteria (Wagner et al., 2011). Wagner, Keller, et al. (2012) found that perceived general disapproval, indicating having experienced low social acknowledgement as a bereaved individual, was strongly correlated with complicated grief and PTSD symptoms.

\section{Other Psychosocial Outcomes}

Those bereaved by euthanasia and PAS felt more prepared for and accepting of the death of their family member than those who were bereaved by natural causes, and they were more likely to believe that they had honored their family member's choices (Ganzini et al., 2009). There were no differences in their endorsement of the importance of caring for the ill family member or in the degree that they felt burdened by the care (Ganzini et al., 2009).

Similarly, participants in qualitative studies reported that their involvement in the decision-making process helped them to anticipate the death (Srinivasan, 2018) and to resolve moral dilemmas regarding their involvement in the decision-making process (Gamondi et al., 2013; Gamondi et al., 2018). Participants reported that honoring the patient's wish and autonomy facilitated an easier grief reaction.

Ganzini et al. (2009) found no difference in social support after the loss between those bereaved by euthanasia or PAS and those bereaved by natural causes (Ganzini et al., 2009). Participants in qualitative studies reported feelings of isolation, selective disclosure, and fear of stigma 
(Gamondi et al., 2013; Gamondi et al., 2018; Starks et al., 2007; Srinivasan, 2018). Some participants reported having little time for their own emotions after the death because of the police investigation, fear of being prosecuted, worrying about dealing with authorities, or feeling guilty for having violated a social rule (Gamondi et al., 2013). Some relatives questioned their own role in the death or wondered if they had contributed to killing their loved one (Srinivasan, 2018; Starks et al., 2007).

\section{Discussion}

This was the first systematic review of the grief and mental health outcomes of people bereaved by euthanasia or PAS. The review identified 10 research articles published over the past 25 years, all conducted in only three of the countries where euthanasia or PAS are permitted. While assisted dying is legal primarily in Western countries, it is unknown whether the study findings may apply to other countries. All studies involved bereaved adults, including older adults, but there have been no studies that included children or adolescents.

All studies reported on grief and/or mental health outcomes (Ganzini et al., 2009; Wagner, Müller, et al., 2012; Swarte et al., 2003). Although the number of studies involving a control group was limited, these studies reported that those bereaved by euthanasia or PAS had similar (Ganzini et al., 2009; Wagner, Müller, et al., 2012) or better (Swarte et al., 2003) scores on measures of disordered grief, grief symptom severity, depressive disorder, severity of current depressive symptoms, and PTSD. However, in the Swarte et al. (2003) study, there were more adult children and siblings in the control group than in the euthanasia group, although the impact of this difference on study findings is unknown. Only one study found a higher prevalence of depression and PTSD in the study group (Wagner, Müller, et al., 2012). However, the control group consisted of the general - not necessarily bereaved - population, whereas the control group in the two other studies comprised a "naturally" bereaved population (Ganzini et al., 2009; Swarte et al., 2003).

Some, mainly qualitative, studies reported specific issues faced by people bereaved by euthanasia/PAS. The main difficulties concerned moral or ethical conflicts, dealing with feelings of guilt and responsibility, dealing with authorities after the death, or coping with anticipated unfavorable social perceptions or judgment regarding the death. A sense of control both from the perspective of the bereaved and the dying family member, anticipating the death, the opportunity to "finish business," and the feeling of having honored the deceased's will were the main positive aspects reported.
There are similarities and differences between euthanasia or PAS, and other modes of death, which may impact the grief of bereaved individuals (Srinivasan, 2018; Wagner, Müller, et al., 2012). Some features may be unique to euthanasia and PAS. People bereaved through euthanasia and PAS can say goodbye and prepare for the loss, for example, through family conversations, as with nonassisted deaths after chronic illnesses (Wright et al., 2008). However, this is different from sudden deaths, which may leave the bereaved individuals with "unfinished business" in their relationship with the deceased that may increase their risk of grief complications (Hui, 2015; Kristensen et al., 2012). With euthanasia and PAS, the bereaved people may have had the opportunity of being involved in the decision-making process and to accept the deceased's desires (Ganzini et al., 2009; Swarte et al., 2003). Nevertheless, being involved in the decision was also reported as confronting them with difficult moral and ethical dilemmas, relational issues prior to the death, as well as experiencing feelings of guilt and wondering about responsibility afterwards (Starks et al., 2007). However, most bereaved people experienced the moral dilemmas as beneficial for their grief, and they were aware that they had gone through a profound process (Gamondi et al, 2018).

As with a death by suicide, the bereaved person is confronted with the intentional death of a significant other. Most of the bereaved people did not consider PAS as a suicide or euthanasia as a murder, although some individuals in their social environment did (Srinivasan, 2018). Like bereavement by unnatural deaths, such as suicide, drug overdose, or accidents (Feigelman, Cerel, \& Sanford, 2018), those bereaved by euthanasia and PAS anticipated negative reactions, for example, through selective sharing of information about the manner of death and self-chosen isolation (Gamondi et al., 2013), which can have an adverse effect on their grief and mental health.

Although there may be international differences (Gamondi et al., 2013), some bereaved people experienced a general lack of openness in society, so that they experienced disenfranchised grief (Srinivasan, 2018). Unresolved grief questions, lack of social support, and perceived stigma may increase their risk of disordered grief and negative mental health (Lobb et al., 2010; Oexle, Feigelman, \& Sheehan, 2018; Pitman et al., 2017; Wagner, Keller, et al., 2012). Furthermore, depending on the legislation in a given country, there may be an investigation by police, medical examiners, or coroners (Biddle, 2003; Spillane et al., 2019). While such investigations can be an intrusive experience, sometimes resulting in greater mental health issues (Wagner et al., 2011), they can also provide opportunities to offer bereavement support through designated mental health and community services such as support groups (Mowll, Smith, \& Fitzpatrick, 2017). Clinicians should be aware 
that those bereaved by euthanasia or PAS may have gone through a long process of caring for their ill family member, struggled with moral dilemmas and feelings of guilt, and may find it difficult to share their experiences in their social environment. Moreover, one should consider that perceived general disapproval is a risk factor for PTSD and complicated grief symptoms (Wagner, Keller, et al., 2012). Reducing and avoiding discriminating or stigmatizing attitudes before and after the death may ease the aftermath of euthanasia or PAS (Wagner et al., 2011).

\section{Limitations and Implications}

The review included only 10 articles reporting on eight studies from three countries, and it is not known whether findings apply to other countries. All the studies are retrospective and mostly measure self-reported outcomes or elicit issues at one point in time. Longitudinal research from various countries is needed to shed light on the course of grief and mental health of people bereaved by PAS and euthanasia. Research should also examine social support, help-seeking, and factors that may hinder or facilitate beneficial or adverse grief outcomes. Future research could also investigate the pathology involved (somatic vs. mental illness) and whether outcomes regarding euthanasia and PAS cases would be different.

The response rate is known for only half of the studies and it varied from $23 \%$ to $75 \%$. Moreover, very little is known about possible differences between responders and nonresponders regarding consequences of assisted dying in their life. In the Gamondi et al. (2013) study, the only study addressing this issue, four relatives refused to participate in the study because it would have been too distressing to recall the experience. This may suggest a possible bias of having more favorable outcomes being overrepresented. Similarly, the literature suggests that people with greater grief feelings have higher nonresponse rates (Stroebe \& Stroebe, 1989), indicating that negative grief experiences might be underreported.

Most studies solicited relatives and friends witnessing the death. This seems appropriate when investigating traumatic symptoms but could result in a selection bias when considering bereavement or psychosocial, moral, or relational issues likely to influence the bereavement. People having opted for not witnessing the death might face specific challenges and have different grief reactions. Gamondi et al. (2013) also described the personal moral belief of the respondents and its possible influence on their bereavement (relatives with favourable beliefs possibly experienced less troubled bereavement). Further research should address these issues.
Research on grief in other circumstances suggests that some grief experiences may be more pronounced in younger age groups, for example, feelings of anxiety and self-harm (Andriessen, Hadzi-Pavlovic, Draper, Dudley, \& Mitchell, 2018; Balk, 2014). Hence, children and adolescents may face specific challenges in coping with bereavement (Andriessen, Lobb, et al., 2018; Rosner, Kruse, \& Hagl, 2010), and their omission from this field of research signifies a serious gap in our knowledge about how to best prepare or support them in the case of a death by euthanasia or PAS.

The overall quality of the included studies was rated as fair. To improve study quality, future studies should involve representative samples, include control groups of people bereaved by other modes of death, and apply standardized measures of grief and mental health-related outcomes.

\section{Conclusion}

Despite the many challenges associated with bereavement after euthanasia and PAS, the findings of this review suggest that the psychosocial aftermath of this type of death is not worse than that of other types of death. Nevertheless, those bereaved may have to cope with the social perception of assisted dying and with moral and relational issues within the family. Obviously, as more countries are regulating assisted dying, high-quality studies across the lifespan are needed to investigate the grief and the psychosocial aftermath of these deaths and the factors that may hinder or facilitate the grief trajectories of the bereaved. These studies should be based on representative samples and involve those who contested the deceased's will or opted for not witnessing the death.

\section{References}

Andriessen, K., Hadzi-Pavlovic, D., Draper, B., Dudley, M., \& Mitchell, P. B. (2018). The Adolescent Grief Inventory: Development of a novel grief measurement. Journal of Affective Disorders, 240, 203-211. https://doi.org/10.1016/j.jad.2018.07.012

Andriessen, K., Lobb, E., Mowll, J., Dudley, M., Draper, B., \& Mitchell, P. B. (2018). Help-seeking experiences of bereaved adolescents: a qualitative study. Death Studies. Advance online publication. https://doi.org/10.1080/07481187.2018.1426657

Arrindell, W. A., \& Ettema, J. H. M. (1986). SCL-90: Handleiding bij een multidimensionele psychopathologie-indicator [Manual of a multidimensional indicator of psychopathology]. Lisse, The Netherlands: Swets Test Publishers.

Balk, D. E. (2014). Dealing with dying, death, and grief during adolescence. New York, NY: Routledge.

Beder, J. (1998). Bereavement after a physician-assisted suicide: A speculation based on theory. Suicide and Life-Threaten- 
ing Behavior, 28(3), 302-308. https://doi.org/10.1111/j.1943278X.1998.tb00859.x

Beck, A. T., Steer, R. A., \& Carbin, M. G. (1988). Psychometric properties of the Beck Depression Inventory: Twenty-five years of evaluation. Clinical Psychology Review, 8(1), 77-100. https://doi. org/10.1016/0272-7358(88)90050-5

Bélanger, E., Towers, A., Wright, D. K., Chen, Y., Tradounsky, G., \& Macdonald, M. E. (2019). Of dilemmas and tensions: A qualitative study of palliative care physicians' positions regarding voluntary active euthanasia in Quebec, Canada. Journal of Medical Ethics, 45(1), 48-53. https://doi.org/10.1136/medethics-2017-104339

Biddle, L. (2003). Public hazards or private tragedies? An exploratory study of the effect of coroners' procedures on those bereaved by suicide. Social Science \& Medicine, 56(5), 1033-1045. https://doi.org/10.1016/S0277-9536(02)00097-7

Boelen, P. A., Van den Bout, J., De Keijser, J., \& Hoijtink, H. (2003). Reliability and validity of the Dutch version of the Inventory of Traumatic Grief (ITG). Death Studies, 27(3), 227-247. https://doi. org/10.1080/07481180302889

Bundesamt für Statistik [Federal Statistical Office]. (2019). Cause of death statistics 2016. Retrieved from https://www.bfs.admin. ch/bfs/en/home/statistics/catalogues-databases/publications.assetdetail.3902308.html

Carr, D. (2003). A "good death" for whom? Quality of spouse's death and psychological distress among older widowed persons. Journal of Health and Social Behavior, 44(2), 215-232. https:// www.jstor.org/stable/1519809

Castelli Dransart, D. A., Scozzari, E., \& Voélin, S. (2017). Stances on assisted suicide by health and social care professionals working with older persons in Switzerland. Ethics \& Behavior, 27(7), 599-614. https://doi.org/10.1080/10508422.2016.1227259

Chapple, A., Ziebland, S., Simkin, S., \& Hawton, K. (2013). How people bereaved by suicide perceive newspaper reporting: Qualitative study. The British Journal of Psychiatry, 203(3), 228-232. https://doi.org/10.1192/bjp.bp.112.114116

Cohen, J., Dierickx, S., Penders, Y. W., Deliens, L., \& Chambaere, K. (2018). How accurately is euthanasia reported on death certificates in a country with legal euthanasia: A population-based study. European Journal of Epidemiology, 33(7), 689-693. https://doi.org/10.1007/s10654-018-0397-5

Cohen, J., Marcoux, I., Bilsen, J., Deboosere, P., van der Wal, G., \& Deliens, L. (2006). European public acceptance of euthanasia: Socio-demographic and cultural factors associated with the acceptance of euthanasia in 33 European countries. Social Science \& Medicine, 63(3), 743-756. https://doi.org/10.1016/j. socscimed.2006.01.026

Dees, M. K., Vernooij-Dassen, M. J., Dekkers, W. J., Vissers, K. C., \& Van Weel, C. (2011). ‘Unbearable suffering': A qualitative study on the perspectives of patients who request assistance in dying. Journal of Medical Ethics, 37(12), 727-734. https://doi. org/10.1136/jme.2011.045492

Dowbiggin, I. (2005). A concise history of euthanasia: Life, death, God, and medicine. Lanham, MD: Rowman \& Littlefield.

Dyer, O., White, C., \& Rada, A. G. (2015). Assisted dying: Law and practice around the world. British Medical Journal, 351, h4481. https://doi.org/10.1136/bmj.h4481

Dyregrov, K., Cimitan, A., \& De Leo, D. (2014). Reactions to traumatic death. In D. De Leo, A. Cimitan, K. Dyregrov, O. Grad, \& K. Andriessen (Eds.), Bereavement after traumatic death: Helping the survivors (pp. 19-35). Boston, MA: Hogrefe Publishing.

Emanuel, E. J. (1994). The history of euthanasia debates in the United States and Britain. Annals of Internal Medicine, 121(10), 793-802. https://doi.org/10.7326/0003-4819-121-10199411150-00010

Emanuel, E. J., Onwuteaka-Philipsen, B. D., Urwin, J. W., \& Cohen, J. (2016). Attitudes and practices of euthanasia and physi- cian-assisted suicide in the United States, Canada, and Europe. JAMA, 316(1), 79-90. https://doi.org/10.1001/jama.2016.8499

Faschingbauer, T. R., Zisook, S., \& DeVaul, R. (1987). The Texas Revised Inventory of Grief. In S. Zisook (Ed.), Biopsychosocial aspects of bereavement (pp. 127-138). Washington, DC: American Psychiatric Press.

Federale Overheidsdienst Volksgezondheid, Veiligheid van de Voedselketen, en Leefmilieu. (2019). Euthanasie: Cijfers voor het jaar 2018 [Euthanasia: Data 2018]. Retrieved from https:// overlegorganen.gezondheid.belgie.be/nl/documenten/euthanasie-cijfers-voor-het-jaar-2018

Feigelman, W., Cerel, J., \& Sanford, R. (2018). Disclosure in traumatic deaths as correlates of differential mental health outcomes. Death Studies, 42(7), 456-462. https://doi.org/10.1080 /07481187.2017.1372533

Frey, L. M., \& Hans, J. D. (2016). Attitudes toward assisted suicide: Does family context matter? Archives of Suicide Research, 20(2) 250-264. https://doi.org/10.1080/13811118.2015.1004477

Ganzini, L., Dobscha, S. K., Heintz, R. T., \& Press, N. (2003). Oregon physicians' perceptions of patients who request assisted suicide and their families. Journal of Palliative Medicine, 6(3), 381390. https://doi.org/10.1089/109662103322144691

Ganzini, L., Goy, E. R., Dobscha, S. K., \& Prigerson, H. (2009). Mental health outcomes of family members of Oregonians who request physician aid in dying. Journal of Pain and Symptom Management, 38(6), 807-815. https://doi.org/10.1016/j.jpainsymman.2009.04.026

Gamondi, C. (2017). Relatives' experiences in assisted suicide decision-making: Overview of the literature with specific focus on the Swiss experience. In G. Borasio, R. Jox, J. Taupitz, \& U. Wiesing (Eds.), Assistierter Suizid: Der Stand der Wissenschaft (pp. 41-50). Berlin, Germany: Springer. https://doi.org/10.1007/9783-662-52669-9_5

Gamondi, C., Pott, M., Forbes, K., \& Payne, S. (2013). Exploring the experiences of bereaved families involved in assisted suicide in Southern Switzerland: A qualitative study. BMJ Supportive and Palliative Care, 5(2), 146-152. https://doi.org/10.1136/bmjspcare-2013-000483

Gamondi, C., Pott, M., Preston, N., \& Payne, S. (2018). Family caregivers' reflections on experiences of assisted suicide in Switzerland: A qualitative interview study. Journal of Pain and Symptom Management, 55(4), 1085-1094. https://doi.org/10.1016/j. jpainsymman.2017.12.482

Hendry, M., Pasterfield, D., Lewis, R., Carter, B., Hodgson, D., \& Wilkinson, C. (2013). Why do we want the right to die? A systematic review of the international literature on the views of patients, carers and the public on assisted dying. Palliative Medicine, 27(1), 13-26. https://doi.org/10.1177/0269216312463623

Higgins, J. P., \& Green, S. (Eds.). (2011). Cochrane handbook for systematic reviews of interventions Version 5.1.0 (updated March 2011). London, UK: The Cochrane Collaboration. Retrieved from http://handbook.cochrane.org

Horowitz, M., Wilner, N., \& Alvarez, W. (1979). Impact of Event Scale: A measure of subjective stress. Psychosomatic Medicine, 41(3), 209-218. http://dx.doi.org/10.1097/00006842-197905000-00004

Hui, D. (2015). Unexpected death in palliative care: What to expect when you are not expecting. Current Opinion in Supportive and Palliative Care, 9(4), 369-374. https://doi.org/10.1097/ SPC.0000000000000174

Kelleher, M. J., Chambers, D., Corcoran, P., Keeley, H. S., \& Williamson, E. (1998). Euthanasia and related practices worldwide. Crisis, 19(3), 109-115. https://doi.org/10.1027/02275910.19.3.109

Kelleher, M., Clark, D., Goldney, B., Kerkhof, A., Wasserman, J., \& Wedler, H. (1995). IASP Task Force on euthanasia and assisted suicide. Crisis, 16(3), 111-115, 120. https://doi.org/10.1027/02275910.16.3.111 
Kimsma, G. K., \& van Leeuwen, E. (2007). The role of family in euthanasia decision making. HEC Forum, 19(4), 365-373. https:// doi.org/10.1007/s10730-007-9048-z

Kristensen, P., Weisæth, L., \& Heir, T. (2012). Bereavement and mental health after sudden and violent losses: A review. Psychiatry, 75(1), 76-97. https://doi.org/10.1521/psyc.2012.75.1.76

Kouwenhoven, P. S., van Thiel, G. J., van der Heide, A., Rietjens, J. A., \& van Delden, J.J. (2019). Developments in euthanasia practice in the Netherlands: Balancing professional responsibility and the patient's autonomy. European Journal of General Practice, 25(1), 44-48. https://doi.org/10.1080/13814788.2018.1517154

Kuitert, H. M. (1994). Suïcide: Wat is er tegen? Zelfdoding in moreel perspectief (3rd rev. ed.) [Suicide: What is against it? Self-killing in moral perspective]. Baarn, The Netherlands: Ten Have.

Lapierre, S., Castelli Dransart, D., St-Amant, K., Dubuc, G., Houle, M., Lacerte, M. M., \& Maggiori, C. (2018). Religiosity and the wish of older adults for physician-assisted suicide. Religions, 9(3), 66. https://doi.org/10.3390/rel9030066

Leenaars, A., Connolly, J., Cantor, C., EchoHawk, M., He, Z. X., Kokorina, N., ... Takahashi, Y. (2001). Suicide, assisted suicide and euthanasia: International perspectives. Irish Journal of Psychological Medicine, 18(1), 33-37. https://doi.org/10.1017/ S0790966700006224

Lobb, E. A., Kristjanson, L. J., Aoun, S. M., Monterosso, L., Halkett, G. K., \& Davies, A. (2010). Predictors of complicated grief: A systematic review of empirical studies. Death Studies, 34(8), 673698. https://doi.org/10.1080/07481187.2010.496686

Lubin, B. (1965). Adjective checklists for measurement of depression. Archives of General Psychiatry, 12(1), 57-62. https://doi. org/10.1001/archpsyc.1965.01720310059007

Marcoux, I., Mishara, B. L., \& Durand, C. (2007). Confusion between euthanasia and other end-of-life decisions. Canadian Journal of Public Health, 98(3), 235-239. https://doi.org/10.1007/ BF03403719

Mishara, B. L., \& Kerkhof, A. J. (2018). Canadian and Dutch doctors' roles in assistance in dying. Canadian Journal of Public Health, 109(5-6), 726-728. https://doi.org/10.17269/s41997-018-0079-9

Mishara, B. L., \& Weisstub, D. N. (2013). Premises and evidence in the rhetoric of assisted suicide and euthanasia. International Journal of Law and Psychiatry, 36(5-6), 427-435. https://doi. org/10.1016/j.ijlp.2013.09.003

Moher, D., Liberati, A., Tetzlaff, J., Altman, D. G., \& Prisma Group. (2009). Preferred reporting items for systematic reviews and meta-analyses: The PRISMA statement. PLoS Medicine, 6(7), e1000097. https://doi.org/10.1371/journal.pmed.1000097

Mowll, J., Smith, H., \& Fitzpatrick, C. (2017). Supporting families through the forensic and coronial process after a death from suicide. In K. Andriessen, K. Krysinska, \& O. Grad (Eds.), Postvention in action: The international handbook of suicide bereavement support (pp. 162-173). Boston, MA: Hogrefe Publishing.

Oexle, N., Feigelman, W., \& Sheehan, L. (2018). Perceived suicide stigma, secrecy about suicide loss and mental health outcomes. Death Studies. Advance online publication. https://doi. org/10.1080/07481187.2018.1539052

Pitman, A., Rantell, K., Marston, L., King, M., \& Osborn, D. (2017). Perceived stigma of sudden bereavement as a risk factor for suicidal thoughts and suicide attempt: Analysis of British cross-sectional survey data on 3387 young bereaved adults. International Journal of Environmental Research and Public Health, 14(3), 286. https://doi.org/10.3390/ijerph14030286

Poma, S. Z., Vicentini, S., Siviero, F., Grossi, A., Toniolo, E., Baldo, V., \& Leo, D. D. (2015). The opinions of GP's patients about suicide, assisted suicide, euthanasia, and suicide prevention: An Italian survey. Suicide and Life-Threatening Behavior, 45(4), 391-398. https://doi.org/10.1111/sltb.12138

Pott, M., Dubois, J., Currat, T., \& Gamondi, C. (2011). Les proches impliqués dans une assistance au suicide [Relatives involved in assisted suicide]. Revue Internationale de Soins Palliatifs, 26(3), 277-286. https://doi.org/10.3917/inka.113.0277

Prigerson, H. O., \& Jacobs, S. C. (2001). Traumatic grief as a distinct disorder: A rationale, consensus criteria, and a preliminary empirical test. In M. S. Stroebe, R. O. Hansson, W. Stroebe, \& H. Schut (Eds.), Handbook of bereavement research: Consequences, coping, and care (pp. 613-645). Washington, DC: American Psychological Association. https://doi.org/10.1037/10436-026

Rijksoverheid. (2019). Vijftien jaar euthanasiewet: Belangrijkste cijfers 2017 [Fifteen years euthanasia law: Key data 2017]. Retrieved from https://www.euthanasiecommissie.nl/actueel/ nieuws/2018/maart/7/vijftien-jaar-euthanasiewet-belangrijkste-cijfers-2017

Rosner, R., Kruse, J., \& Hagl, M. (2010). A meta-analysis of interventions for bereaved children and adolescents. Death Studies, 34(2), 99-136. https://doi.org/10.1080/07481180903492422

Srinivasan, E. G. (2018). Bereavement and the Oregon Death with Dignity Act: How does assisted death impact grief? Death Studies. Advance online publication. https://doi.org/10.1080/07481 187.2018.1511636

Speijer, N. \& Diekstra, R. F. W. (1980). Hulp bij zelfdoding. Een studie van problemen rondom de hulpverlening bij de zelfgewilde dood [Aid in suicide. A study of the problems regarding aid in self-desired death]. Deventer, The Netherlands: Van Loghum Slaterus.

Spillane, A., Matvienko-Sikar, K., Larkin, C., Corcoran, P., \& Arensman, E. (2019). How suicide-bereaved family members experience the inquest process: A qualitative study using thematic analysis. International Journal of Qualitative Studies on Health and Well-being, 14(1), 1563430. https://doi.org/10.1080/17482 631.2018 .1563430

Starks, H., Back, A. L., Pearlman, R. A., Koenig, B. A., Hsu, C., Gordon, J. R., \& Bharucha, A. J. (2007). Family member involvement in hastened death. Death Studies, 31(2), 105-130. https://doi. org/10.1080/07481180601100483

Steck, N., Egger, M., Maessen, M., Reisch, T., \& Zwahlen, M. (2013). Euthanasia and assisted suicide in selected European countries and US states: Systematic literature review. Medical Care, 51(10), 938-944. https://doi.org/10.1097/MLR. 0b013e3182a0f427

Stroebe, M. S., \& Stroebe, W. (1990). Who participates in bereavement research? A review and empirical study. OMEGA-Journal of Death and Dying, 20(1), 1-29. https://doi.org/10.2190/C3JEC9L1-5R91-DWDU

Swarte, N. B., Van Der Lee, M. L., Van Der Bom, J. G., Van Den Bout, J., \& Heintz, A. P. M. (2003). Effects of euthanasia on the bereaved family and friends: A cross sectional study. British Medical Journal, 327(7408), 189-192. https://doi.org/10.1136/ bmj.327.7408.189

Tong, A., Sainsbury, P., \& Craig, J. (2007). Consolidated criteria for reporting qualitative research (COREQ): A 32-item checklist for interviews and focus groups. International Journal for Quality in Health Care, 19(6), 349-357. https://doi.org/10.1093/intqho/ mzm042

van den Boom, F. (1995). AIDS, euthanasia and grief. AIDS Care, 7(Suppl. 1), 175-185. https://doi.org/10.1080/095401295501 26182

Victoria State Government. (2019). Voluntary assisted dying. Retrieved from https://www2.health.vic.gov.au/hospitals-and-health-services/patient-care/end-of-life-care/voluntary-assisted-dying/

Wagner, B., Boucsein, V., \& Maercker, A. (2011). The impact of forensic investigations following assisted suicide on posttraumatic stress disorder. Swiss Medical Weekly, 141, w13284. https://doi. org/10.4414/smw.2011.13284

Wagner, B., Keller, V., Knaevelsrud, C., \& Maercker, A. (2012). Social acknowledgement as a predictor of post-traumatic stress and 
complicated grief after witnessing assisted suicide. International Journal of Social Psychiatry, 58(4), 381-385. https://doi. org/10.1177/0020764011400791

Wagner, B., Müller, J., \& Maercker, A. (2012). Death by request in Switzerland: Posttraumatic stress disorder and complicated grief after witnessing assisted suicide. European Psychiatry, 27(7), 542-546. https://doi.org/10.1016/j.eurpsy.2010.12.003

Weiss, D. S., \& Marmar, C. R. (1997). The Impact of Event Scale - Revised. In J. Wilson \& T. M. Keane (Eds.), Assessing psychological trauma and PTSD (pp. 399-411). New York, NY: Guilford.

Wells, G. A., Shea, B., O'Connell, D., Peterson, J., Welch, V., Losos, M., \& Tugwell, P. (n.d.). The Newcastle-Ottawa Scale (NOS) for assessing the quality of non-randomised studies in meta-analyses. Retrieved from http://www.ohri.ca/programs/clinical_epidemiology/oxford.asp

Wright, A. A., Zhang, B., Ray, A., Mack, J. W., Trice, E., Balboni, T., ... Prigerson, H. G. (2008). Associations between end-of-life discussions, patient mental health, medical care near death, and caregiver bereavement adjustment. JAMA, 300(14), 1665-1673. https://doi.org/10.1001/jama.300.14.1665

\section{History}

Received May 13, 2019

Revision received July 20, 2019

Accepted July 28, 2019

Published online October 28, 2019

\section{Conflicts of Interest}

The authors have no conflict of interest to report.

\section{Funding}

Dr. Karl Andriessen was supported by a NHMRC Early Career Fellowship (APP1157796). The funding body had no role in the design of the study, the collection, analysis, and interpretation of data, the writing of the report, and the decision to submit it for publication.

\section{ORCID}

Karl Andriessen

(iD) https://orcid.org/0000-0002-3107-1114

\section{Karl Andriessen}

Centre for Mental Health

School of Population and Global Health

The University of Melbourne

Level 4, 207 Bouverie St

Carlton 3053 VIC

Australia

karl.andriessen@unimelb.edu.au

Karl Andriessen, PhD, MSuicidology, is NHMRC ECF Research Fellow in the Centre for Mental Health, School of Population and Global Health, The University of Melbourne, Australia. He has a broad interest in suicide prevention research with a major focus on postvention and grief after suicide and other traumatic deaths.

Karolina Krysinska, PhD, is Research Fellow in Orygen, The National Centre of Excellence in Youth Mental Health, and the Centre for Mental Health, School of Population and Global Health, The University of Melbourne, Australia. She is an experienced research psychologist, whose main interest is research in suicide, prevention, and postvention.

Dolores Angela Castelli Dransart, PhD, is Professor in the School of Social Work Fribourg, HES-SO University of Applied Sciences and Arts Western Switzerland. Her teaching and research interests include the various impacts of suicide and suicidality on families and professionals, postvention, assisted suicide, end-of-life decisions, aging, and identity transitions.

Luc Dargis, MS, is Director of the Documentation Centre of the Centre for Research and Intervention on Suicide, Ethical Issues and End-of-Life Practices (CRISE), Université du Québec à Montréal, Canada, where he supervises the center's information-gathering, documentation research, and knowledge application activities.

Brian Mishara, PhD, is Director of the Centre for Research and Intervention on Suicide, Ethical Issues and End-of-Life Practices (CRISE) and Psychology Professor at the Université du Québec à Montréal, Canada. His research focuses on best practices in suicide prevention, helplines and new technologies, ethics, and medical assistance in dying. He consults and conducts suicide prevention training internationally. 


\section{Appendix}

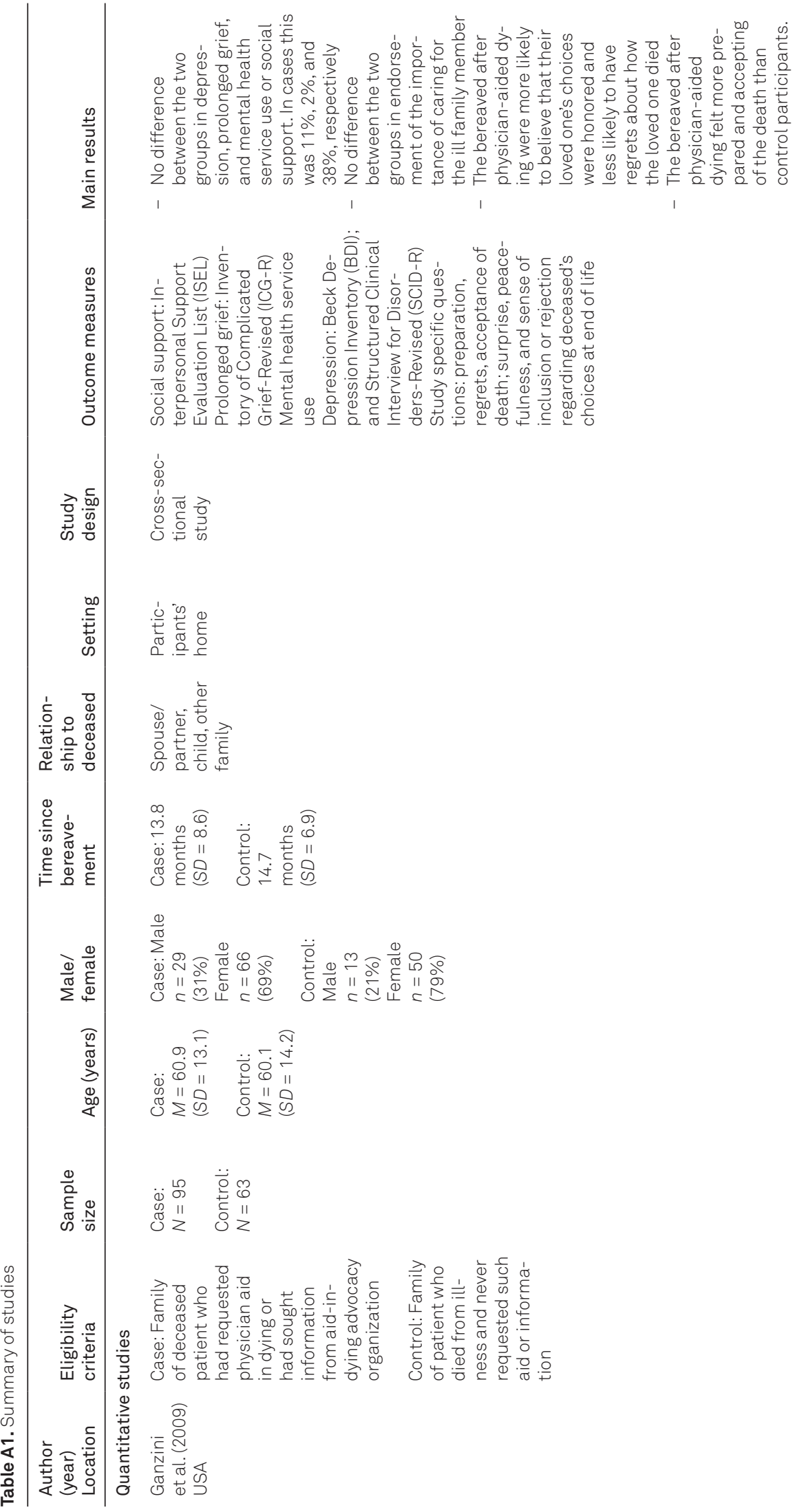




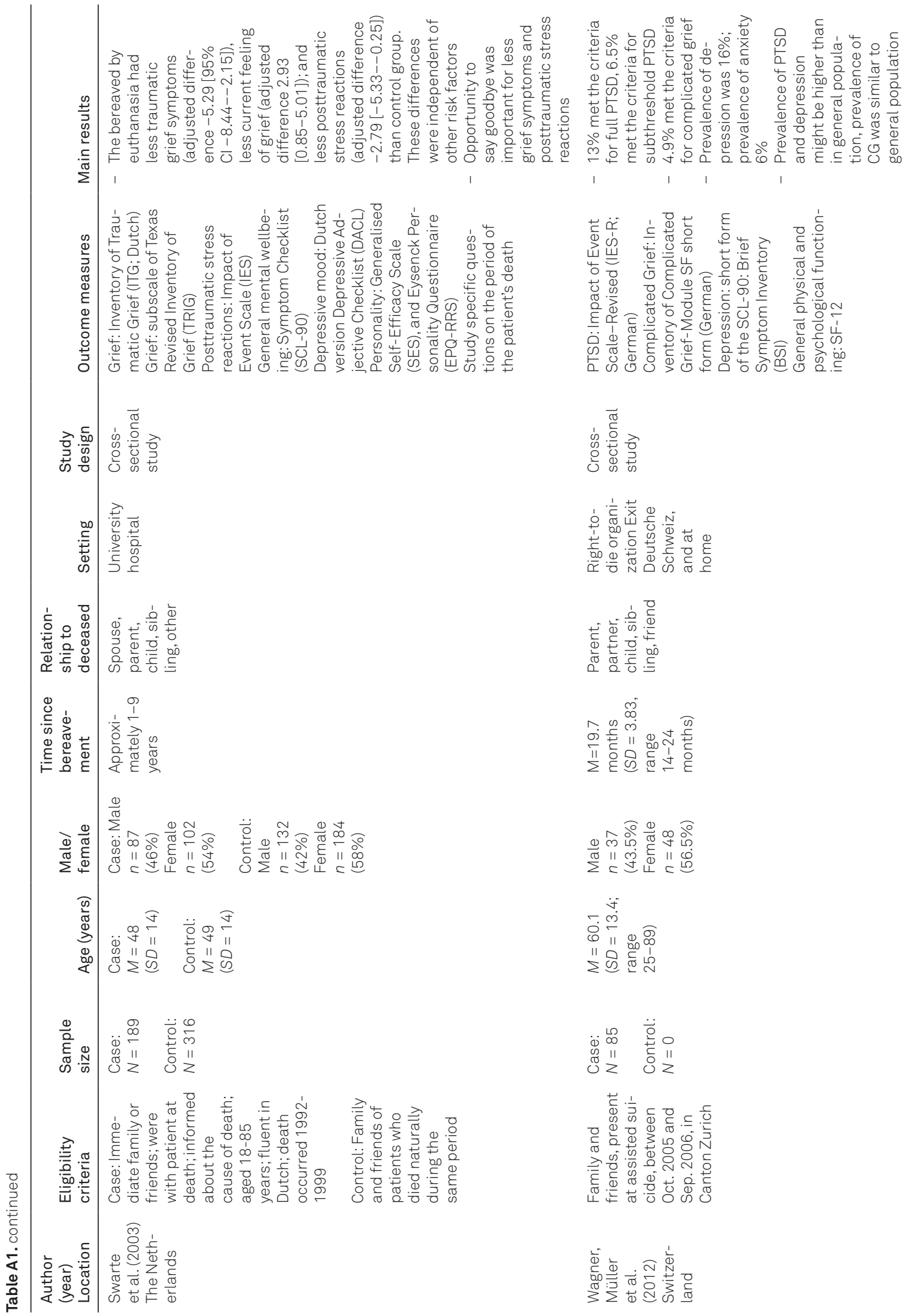




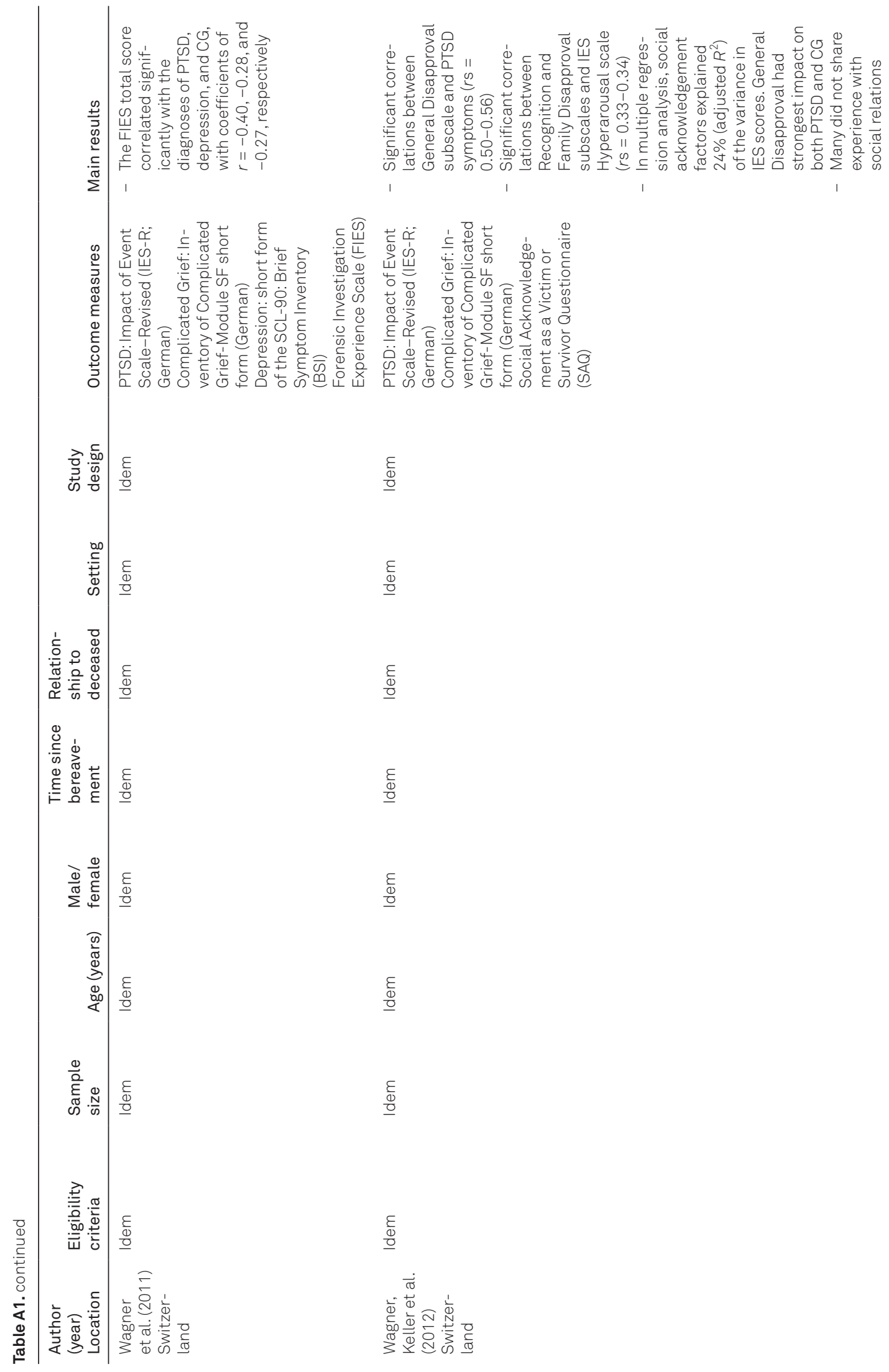




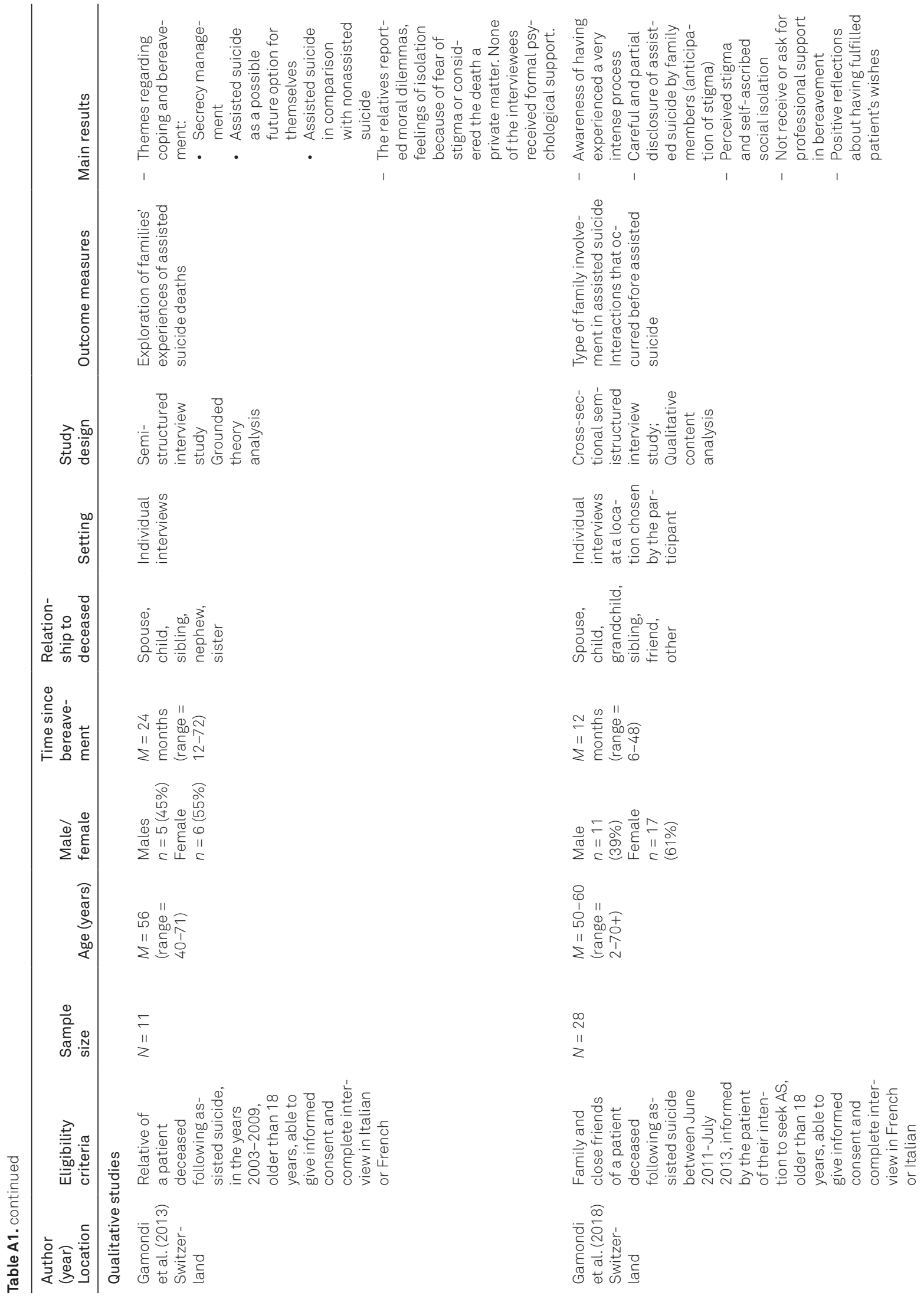




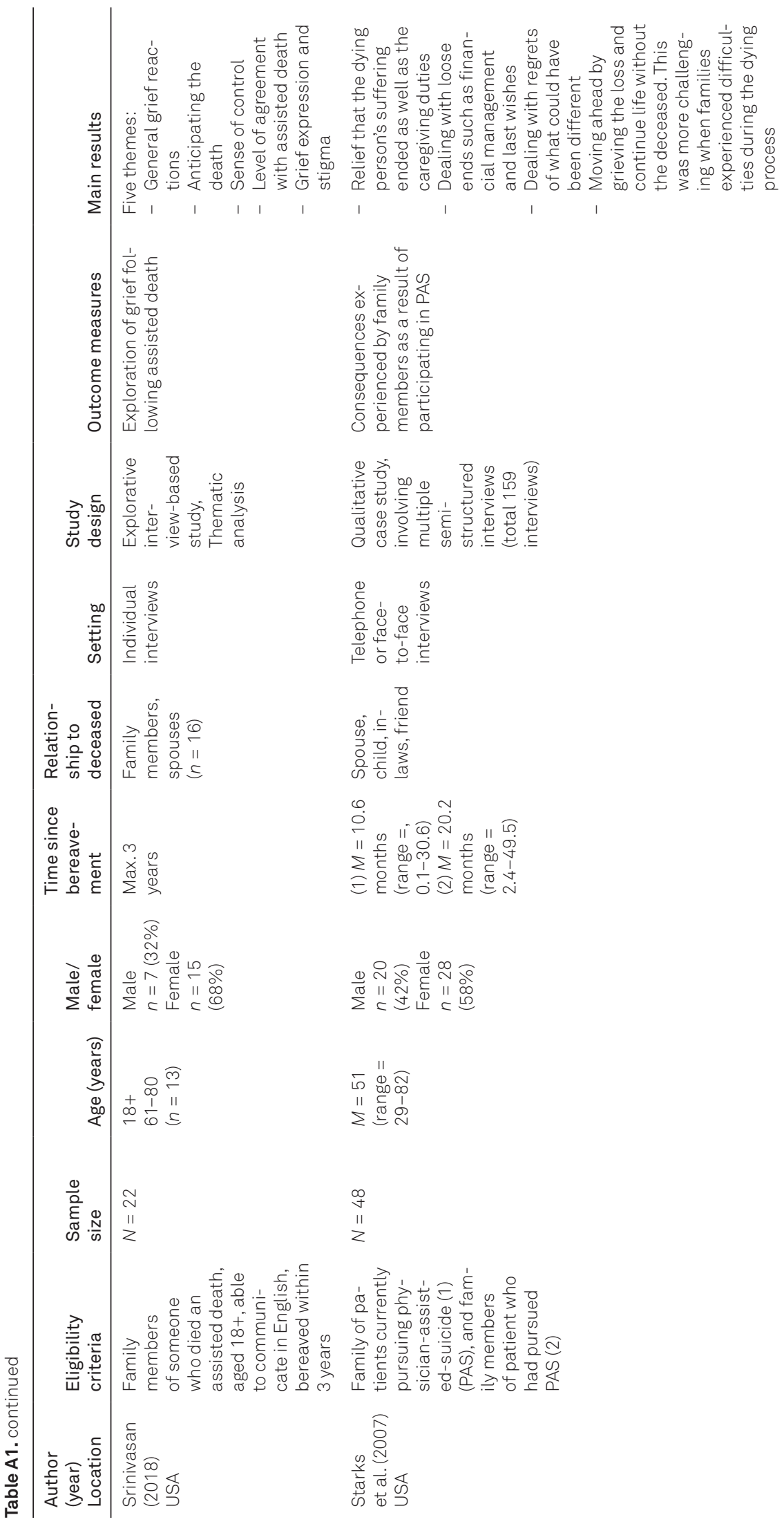




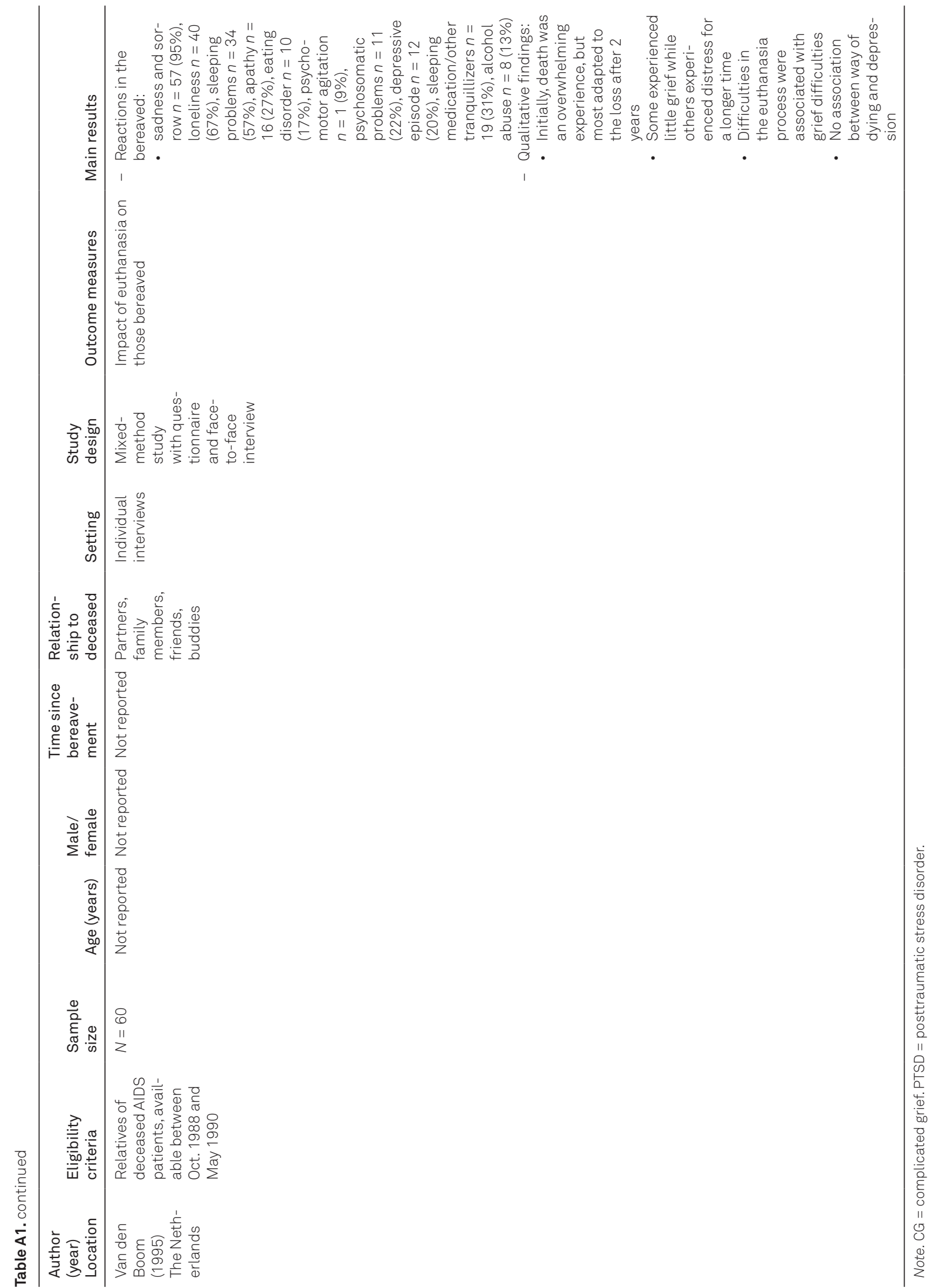

